\title{
UN ESTUDIO DE LA ABUNDANCIA Y ECOLOGIA DE LAS GARZAS (ARDEIDAE) EN EL RIO PACAYA, RESERVA NACIONAL PACAYA-SAMIRIA, PERU
}

Pekka Soini* $^{*}$

\section{RESUMEN}

Se investigó la abundancia y ecología de las garzas en el río Pacaya medio desde 1988 hasta 1992. Se presentan datos de la organización social, preferencias de hábitat y densidades poblacionales para las especies Ardea cocoi, Casmerodius albus, Egretta thula, Butorides striatus, Pilherodius pileatus, Trigrisoma lineatum y Bubulcus ibis.

\section{ABST RACT}

A bundance and ecology of the herons and eggretts were investigated on the middle Pacaya river from 1988 through 1992. Data on social organization, habitat preferences, and population densities are present for Ardea cocoi, Casmerodius albus, Egretta thula, Buttorides striatus, Pilherodius pileatus, Tigrisoma lineatum, and Bubulcus ibis.

Palabras Claves: Ardea cocoi, Casmerodius albus, Egretra thula, Butorides striatus, Pilherodius pileatus, Tigrisoma lineatum, Bubulcus ibis, abundancia, ecología, Reserva Nacional Pacaya-Sarniria.

\section{INTRODUCCION}

Las aves acuáticas constituyen un componente importante del ecosistema acuático de la Amazonía e incluyen varias especies de importancia económica para los habitantes rurales de la región. No obstante, muy poco se sabe sobre la ecología y dinámica poblacional de éstas (e.g. Koepcke y Koepcke, 1964; Hancock y K ushlan, 1984), y hasta ahora no se ha tenido datos sobre densidades poblacionales para ninguna especie o localidad de la A mazonía. Esto es en gran

* Investigador IIAP. A v. A belardo Quiñones Km. 2.5. A partado 784. IquitosPerú. 
parte debido a la magnitud de inversión de tiempo y esfuerzo que se requiere para obtener información cuantitativa fidedigna sobre la abundancia de estas aves.

En el río Pacaya, Reserva Nacional Pacaya-Samiria se ha estado conduciendo, desde 1988, un estudio a largo plazo de la ecología y dinámica poblacional de las aves acuáticas, y en este trabajo se reportan los resultados obtenidos referentes a las especies de garzas (A rdeidae) presentes en el Pacaya medio, con énfasis en los aspectos de la abundancia o densidades poblacionales, preferencias de habitat y organización social. A unque el estudio fue enfocado en las poblaciones del Pacaya medio, se realizaron observaciones adicionales en el sector bajo del mismo río, lo que permitirá hacer algunas comparaciones entre los dos sectores de la cuenca.

La meta más importante de este estudio fue el obtener un conocimiento cuantitativo de la abundancia de aves acuáticas, para lo cual fue necesario desarrollar una metodología apropiada de censo, ya que no se han descrito métodos de censo adecuados para la región. En sección M étodos se describe la metodología desarrollada y en sección Discusión y Conclusiones se presenta una evaluación de la aplicabilidad y efectividad de esta metodología.

\section{DESCRIPCION DEL AREA PRINCIPAL DE ESTUDIO}

El área del presente estudio abarca la zona de la Estación Biológica de Cahuana y un tramo de $60 \mathrm{Km}$. de curso del río Pacaya medio, desde la cocha Tamara, de surcada hasta $2 \mathrm{Km}$. más arriba de la cocha M auca Tapaje (Figura 1). El área consiste en terrenos aluviales, sujetos a inundación estacional, y cuerpos de agua permanente.

Se reconocieron 6 tipos principales de habitat acuáticas en el Pacaya medio:

1. El curso principal del río

2. Tipishcas

3. Cochas

4. Pantanos o pungales

5. Caños, pozas y hondonadas

6. Tahuampa

A continuación se da una breve descripción de éstos.

1. El río tiene, en el tramo del estudio, un ancho de 40-60 ni y en algunos lugares hasta $80 \mathrm{ni}$. Las márgenes son mayormente bajos y permanecen inundadas entre noviembre y junio (principalmente en enero-mayo); también hay tramos cortos de orillas más elevadas, que sólo se inundan en años de crecientes excepcionalmente grandes del río. El curso del río está bordeado 
de bosque alto y maduro, pantanos (pungales) y de vegetación sucesional. Esta última consiste principalmente en vegetación herbácea, predominando las gramíneas Echinocloa polystachya y Paspalum spp ("gramalotales'), y arboladas de Cecropia latiloba y $C$. membranacea ("ceticales"). Durante el estiaje las orillas presentan pequeñas playas de arena, que permanecen libres de cobertura vegetal por 3-4 meses.

2. Tipishcas son tramos meándricos abandonados por el río reciente 0 subrecientemente y cuyas aguas están todavía en comunicación directa con las del río durante todo el año. Predominan las orillas de bosque maduro; los gramalotales, ceticales y playas de arena están característicamente ausentes. Este tipo de habitat está representado en el área de estudio por la tipishca Cahuana (Figura 1), cuyo curso tiene una longitud de $11 \mathrm{~km}$ y ancho de 30-40

$\mathrm{m}$.

3. Las cochas son tramos de antiguos cauces o canales abandonados del río que, por procesos de sedimentación y de colonización por vegetación, han quedado ya semi-aislados o totalmente aislados del curso actual del río (salvo casos de recontacto posterior) por lo menos durante el estiaje. Una cocha o lago puede formarse también por la inundación permanente de un área debido a hundimiento, bloqueamiento y otros procesos de dinámica fluvial (Kalliola y Pukakka, 1993). Vegetación hidromórfica es generalmente abundante y muchas veces toda la cocha queda cubierta de vegetación flotante.

Este tipo de habitat está representado en el área de estudio por las cochas Tamara y M auca Tapaje (figura 1). Tamara es un lago amplio y abierto, con una longitud aproximada de $2 \mathrm{~km}$ (excluyendo el pungal del extremo septentrional) y ancho de $1 \mathrm{~km}$; es de aguas negras y generalmente libre de vegetación acuática durante todo el año, excepto las márgenes que están bordeadas de una faja amplia de vegetación hidromórfica. M auca Tapaje es una cocha menor y en franca transformación a un pungal, con abundante vegetación hidromórfica flotante, que cubre permanentemente casi todo el espejo de agua.

4. Pungales son pantanos abiertos o parcialmente poblados de árboles, predominando la punga (Pseudobombax munguba). En muchos casos constituyen una fase sucesional más avanzada de las cochas y están cubiertas en gran parte 0 totalmente de vegetación hidromórfica permanente. Durante el estiaje (agosto-octubre) los pungales quedan completamente 0 casi completamente desprovistos de agua superficial.

En el área de estudio, el río está bordeado de numerosos pungales, de extensión y desarrollo sucesional muy variables. 
5. Dentro del bosque inundable hay innumerables pequeños caños, pozas y hondonadas. A unque éstos se secan completamente durante el estiaje, queda a menudo agua estancada en las hondonadas y pozas o partes más profundas de los caños hasta muy avanzado del estiaje. En éstos quedan atrapadas concentraciones de peces, que son aprovechados por varias especies de aves piscívoras.

6. Tahuampa comprende el bosque de bajial (Encamación, 1985), estacionalmente inundado. El río empieza a aumentar su caudal en octubrenoviembre y normalmente la tahuampa permanece inundado desde enerofebrero hasta mayo- junio.

\section{METODOS}

\section{TOMA DE DATOS ECOLÓGICOS}

La investigación de la ecología de las aves acuáticas estaba orientada principalmente hacia los aspectos de la abundancia, organización social, preferencias de habitat y cambios estacionales en estos aspectos. Esta investigación se realizó en todo el área de estudio y censo, pero principalmente en el área de Cahuana.

En Cahuana se hicieron recorridos diarios o semanales en canoa a remo por los diferentes tipos de ambientes acuáticos, anotando la presencia (o ausencia) en ellos de las especies en estudio. Durante el estiaje se hicieron también frecuentes incursiones a pie a las pozas y charcos remanentes y aislados del río o tipishca, para observar la utilización de éstos por las aves acuáticas. Al encontrar aves, se tomó nota del tipo, tamaño y composición de las agrupaciones o nidadas sociales en que fueron vistas y del comportamiento interindividual de sus integrantes. $L$ as unidades sociales fueron clasificadas en las siguientes categorías básicas:

SOLITARIOS

PAREJAS

GRUPOS

BANDADAS
Individuos no acompañados por otros de su especie;

Unidades formadas por 2 individuos adultos, aparentemente un macho y una hembra;

Unidades cohesivas formadas por 2 o varios individuos, incluyendo unidades familiares constituidas por 1-2 adultos y su prole;

Unidades aparentemente cohesivas formadas por numerosos individuos; 
CONGREGACIONES Concentraciones temporarias de muchas unidades sociales en un lugar o área particular.

Otro aspecto importante de la organización social es la presencia o ausencia de comportamiento territorial en la especie. $L$ a especie fue considerada territorial si fue vista defender físicamente su entorno contra otros individuos de su especie.

\section{METODOLOGÍA DE CENSO}

L a metodología básica empleada para censar las aves acuáticas consistió en: 1) contar periódicamente todos los ejemplares detectables de éstas a lo largo de un tramo predeterminado de río o tipishca; 2) contar periódicamente todos los ejemplares presentes en una cocha y sus orillas; y 3) contar periódicamente todos los ejemplares presentes en un área circunscrita y predeterminada.

En la modalidad 1), la abundancia se expresa como el número promedio (anual o estacional, según el caso) de aves presentes por cada kilómetro de río (aves/km río); en la modalidad 2), como número promedio de aves presentes en la cocha; y en la modalidad 3) como el número promedio de aves por kilómetro cuadrado (aves $/ \mathrm{km}^{2}$ ). A unque estos 3 estimadores de abundancia no son estrictamente comparables entre sí, sino más bien son mutuamente complementarios, permiten apreciar, en forma cuantificada, diferencias temporales en las preferencias de hábitat (cuando las hay); además, permiten la comparación directa y cuantificada de la abundancia y preferencias de habitat entre especies.

Referente a la modalidad 1), realizamos, entre enero de 1990 y octubre de 1992, 34 recorridos de censo en un tramo de $48 \mathrm{~km}$ del Pacaya medio, ubicado entre la cocha Tamara y Cahuana (Figura 1). Estos se realizaron en un bote de madera equipado con un motor fueraborda de 9HP, a una velocidad de 10-12 $\mathrm{km} / \mathrm{hora}$, en horas de plena luz diurna. Durante el recorrido se registraba el número de aves avistadas. L as aves en tránsito que se encontraban desplazándose en al to vuelo sobre el área no fueron incluidos en los conteos.

En el análisis final cuantitativo de los resultados, se excluyeron los conteos obtenidos en 6 de los recorridos, debido a que las condiciones de censo en que se realizaron no fueron óptimas (hubo mucha lluvia y/o el recorrido no pudo ser concluido dentro de las horas de plena luz), por lo que la muestra efectiva para los fines de censo se reduce a 28 recorridos. Esta muestra cubre todos los meses del ano. 


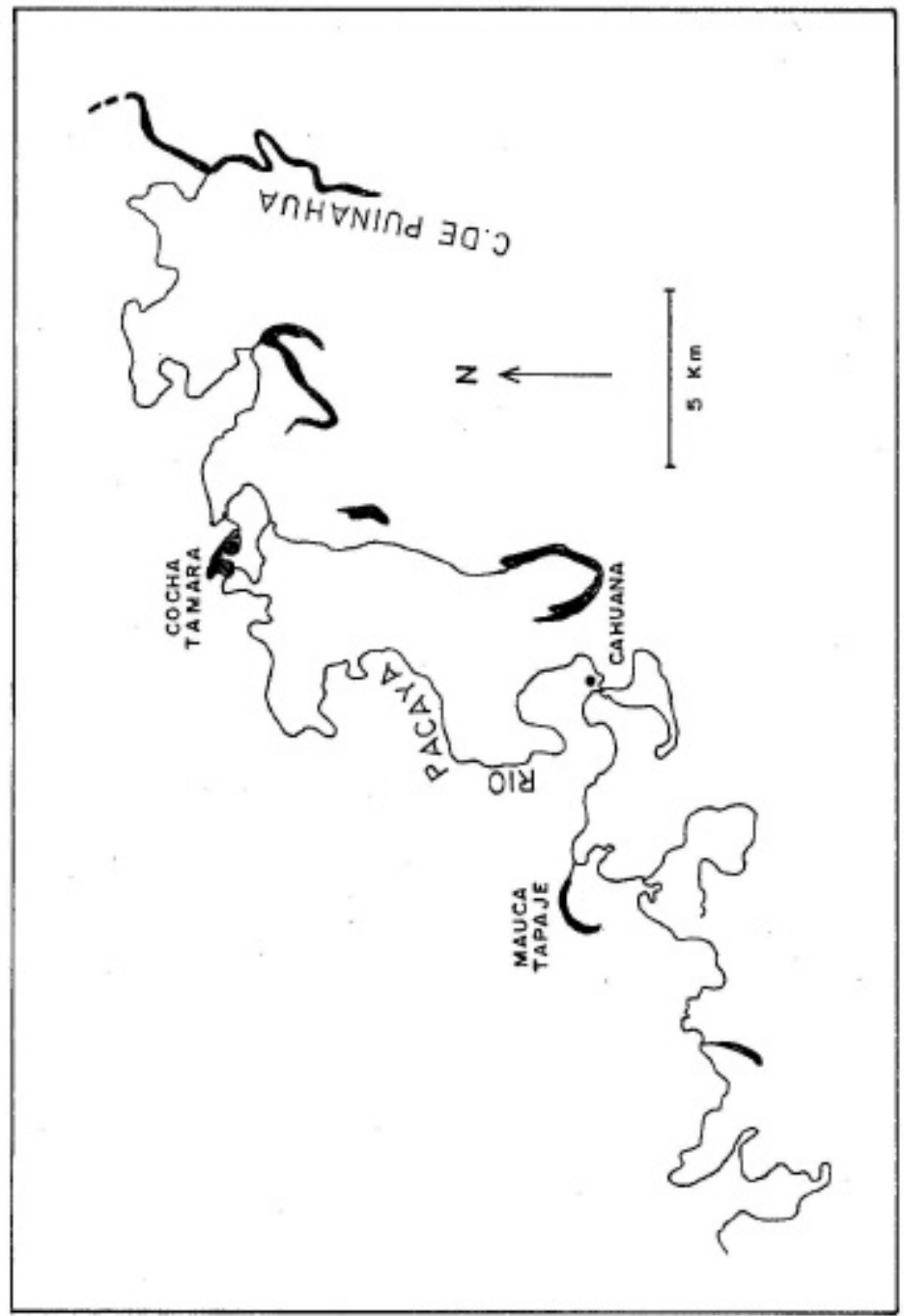

Figura 1. El bajo y medio río Pacaya 
Para obtener otra muestra de río más arriba, realizamos 19 recorridos adicionales en el tramo Cahuana - M auca Tapaje, de $12 \mathrm{~km}$ de longitud. En vista de que el censo de este tramo fue menos completo (por el menor número de recorridos y por no cubrir los meses de abril, mayo y noviembre), los resultados obtenidos en los dos tramos se analizan separadamente.

En la tipishca Cahuana realizamos, entre 1988 y 1991, un total de 136 recorridos de conteo de aves, en 2 tramos predeterminados y separados entre sí (Figura 2), de $2 \mathrm{~km}$ (tramo A) y de $3 \mathrm{~km}$ (tramo B) de longitud. Estos se realizaron en canoa a remo y cubren todos los meses del año.

Referente a la modalidad 2), se realizaron en la cocha Tamara, en 1989-92, 38 conteos totales de estas aves. Después de algunos conteos iniciales en la cocha M auca Tapaje, ésta se quedó completamente cerrada por vegetación hidromórfica y el censo tuvo que ser suspendido; sin embargo, se continué haciendo algunas observaciones ecológicas allá. El censo de Tamara cubre todos los meses del año. Referente a la modalidad 3), se registró en la Estación Biológica de Cahuana, en el período 1989-92, semidiariamente o semanalmente, el número de aves acuáticas presentes en un tramo de $1.5 \mathrm{~km}$ del río frente a la estación y se realizaba frecuentes observaciones y conteos adicionales en el área circundante. En base a estos registros, y los conteos de aves en la tipishca Cahuana, se estimó mensualmente el número de aves presentes en Cahuana, dentro de un área circunscrita de $1.75 \mathrm{~km}^{2}$ (Figura 2). A proximadamente 95 ha de este área consiste en caños, pozas, pantanos, orillas abiertas y cuernos de agua; los restantes 80 ha corresponden al interior del bosque que no forma parte del hábitat de las aves acuáticas. Los cómputos de densidades poblacionales se basan en la primera cifra $\left(0.95 \mathrm{~km}^{2}\right)$, por ende estiman las densidades ecológicas de estas especies en el área de Cahuana. En este censo mensual no se incluyó las aves de transito que permanecieron sólo por momentos o por un día en el área.

\section{RESULTADOS}

En el río Pacaya hemos registrado la presencia de las siguientes 10 especies de garzas:

Ardea cocoi

Casmerodius albus

Egretta thula

Bubulcus ibis

Butorides striatus

Pilherodius pileatus

Tigrisoma lineatum

Nycticorax nycticorax

Cochlearius cochlearius

Agamia agamí garza ceniza

garza blanca grande

garza blanca chica

garza blanca "vaquera'

garza tamanquita

garza blanca

puma garza

garza nocturna

huapapa

guanuy 


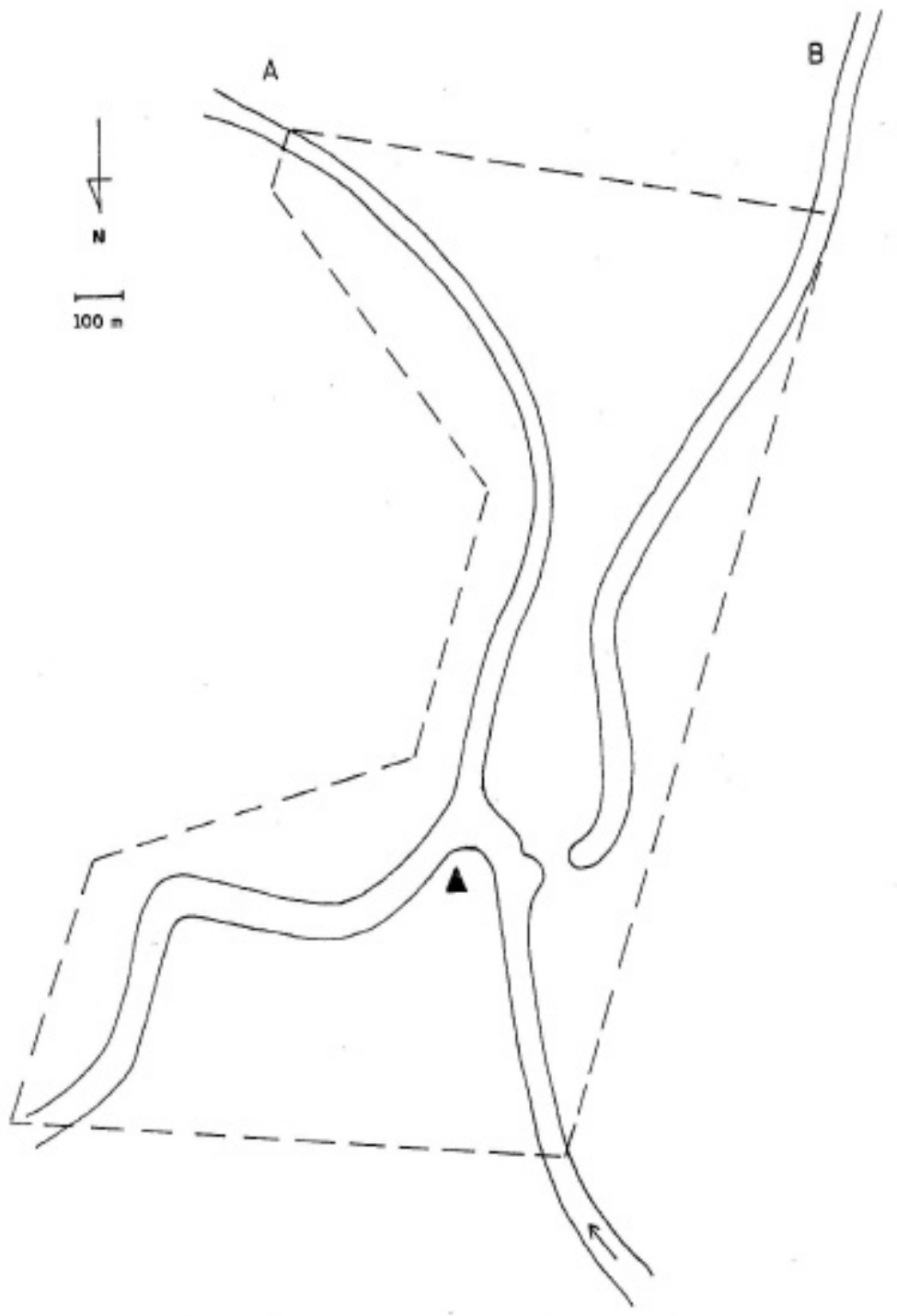

Figura 2. El área de censo en Cahuana, río Pacaya 
De éstas, la última (A. agami) ha sido visto sólo dos veces en el Pacaya medio y ninguna vez en el bajo Pacaya; en ambos casos se trataba de un animal solitario en tránsito; aparentemente esta especie es muy rara o no pertenece a la avifauna del bajo y medio Pacaya.

Las dos especies de hábitos completamente nocturnos, $N$. nycticorax y $C$. cochlearius, no fueron incluidas en este estudio. Según nuestras observaciones circunstanciales en Cahuana y áreas aledañas, N. nycticorax es sólo un visitante esporádico o temporal en el Pacaya medio; probablemente es una especie más propia del bajo Pacaya. C. cochlearius, en cambio, está presente en el Pacaya medio durante todo el año y estimamos que en el área de Cahuana viven mayormente 3-7 aves de esta especie. A continuación se describen la organización social, preferencias de habitat y abundancia de las siete especies diurnas presentes en el bajo y medio Pacaya.

\section{Ardea cocoi, GARZA CENIZA}

Esta es la garza más grande de la Amazonía (peso 1.5 - 2 kg); es mayormente solitaria, con tendencia a territorialidad. Para desplazamiento locales se juntan a menudo 2 - 20 aves y se observan ocasionalmente congregaciones de hasta unas 100 aves. Es parcialmente sedentario: en Cahuana se observan individuos que permanecen en el mismo lugar por meses y otros que se mueven más ampliamente, evidentemente siguiendo cardúmenes de peces migrantes.

\section{Preferencias de habitat}

Habita principalmente las márgenes del río y tipishca; en las cochas es mucho menos frecuente (Tabla 1). También ocupa los pungales, excepto durante el estiaje. A pesar de su gran tamaño, penetra a menudo al interior de la tahuampa, particularmente para cazar peces en las orillas de pequeños caños y pozas o claros.

\section{Abundancia}

Los censos y registros mensuales en Cahuana (Cuadro I A) demuestran que la especie está presente en el área durante todo el año, y que el número de aves presentes fluctúa mayormente entre 3 y 6 . Los conteos no muestran un patrón nítido de fluctuación estacional (Cuadro I A) y en término medio hay 5 aves en el área de Cahuana. La densidad poblacional correspondiente sería 5.3 aves $/ \mathrm{km}^{2}$

L os conteos obtenidos en el tramo Cahuana-Tamara fluctúan entre 9 y 75 aves (Cuadro 18). La abundancia mediana sería 22 aves, lo que equivale 0.46 
aves/km río. En este tramo, la máxima abundancia se observa en junio-julio y la mínima en diciembre - enero y en marzo (Cuadro 1B). Este concuerda con nuestras observaciones generales de que a partir de fines de $M$ ayo 0 en Junio se observa un potable incremento de esta especie en el Pacaya medio, probablemente debido a la

aparición (reclutamiento) sincronizada de las crías del año en la población (Soíni, 1992). La reducción de la población en diciembre es debido a que una gran parte de la población emigra entonces hacia el bajo Pacaya. La poca presencia de estas garzas entre marzo y mayo se debe a que una gran parte de la población se encuentra entonces congregada en las colonias de anidación (garzales).

En el tramo Cahuana - M auca los conteos variaban entre 2 y 7 aves (Cuadro ( C), con un promedio de 4.9 y mediana de 5 , lo que equivale 0.41 aves $/ \mathrm{km}$ río, como término medio. Esto no difiere mucho del valor obtenido en el tramo principal de censo, por lo que consideramos 0.46 aves $/ \mathrm{km}$ río, como representativo para todo el Pacaya medio.

La frecuencia de estas garzas en la cocha Tamara fue baja (Cuadro 1 D), lo que refleja la poca preferencia que tiene por este tipo de hábitat. En término medio hubo 0.55 aves allá.

También en el Bajo Pacaya la especie está presente durante todo el año. En julio-diciembre se observa la mayor abundancia de éstas en las márgenes del río. 


\section{Cuadro 1}

Censo de Ardea cocoi. A: Censos mensuales en el área de Cahuana $\left(1.75 \mathrm{~km}^{2}\right)$. B: Conteos mensuales en el tramo Cahuana-Tamara (48 kms). C: Conteos en el tramo Cahuana-M auca (12 kms). D: Conteos en la cocha Tamara.

\begin{tabular}{|c|c|c|c|c|c|c|c|c|c|c|c|c|}
\hline $\mathrm{ANO}$ & $E$ & $\mathrm{~F}$ & $\mathrm{M}$ & $\mathrm{A}$ & $M$ & $\mathrm{~J}$ & $\mathrm{~J}$ & $\mathrm{~A}$ & $\mathrm{~S}$ & 0 & $\mathrm{~N}$ & $\mathrm{D}$ \\
\hline \multicolumn{13}{|c|}{ A. Cahuana } \\
\hline 89) & $4-6$ & $5-7$ & $6-8$ & $1-2$ & $1-3$ & $3-6$ & $x$ & $6-9$ & $4-6$ & $5-7$ & $4-5$ & $3-5$ \\
\hline 90) & $4-6$ & $x$ & 2 & $3-5$ & $3-5$ & $3-5$ & $4-5$ & $5-6$ & $5-6$ & $5-6$ & $4-5$ & $2-3$ \\
\hline 91) & - & - & $2-3$ & - & $4-6$ & - & - & - & $4-6 x$ & & $x$ & $x$ \\
\hline 92) & $x$ & - & $x$ & - & - & - & - & $5-6$ & $5-6$ & $6-7$ & - & - \\
\hline
\end{tabular}

B. Cahuana-Tamara $(n=28)$

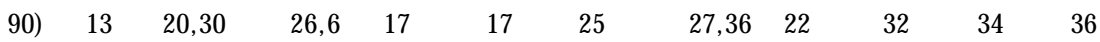
5,10

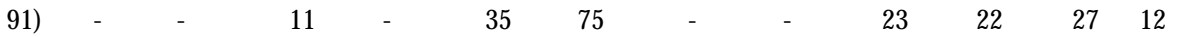

\begin{tabular}{lllllllllllll} 
92) & 18 & - & 9 & - & - & - & - & 15 & 18 & 22 & - & - \\
\hline
\end{tabular}

C. Cahuana - M auca $(n=19)$

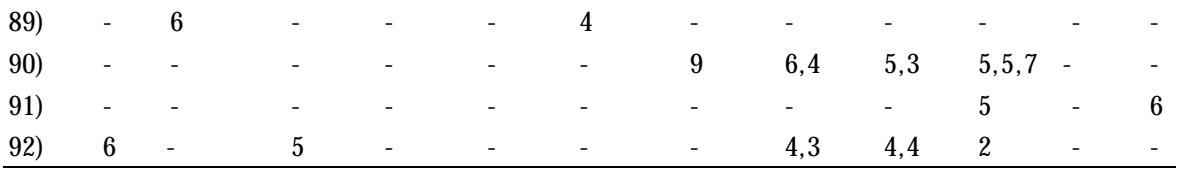

D. Cocha Tamara $(n=38)$

\begin{tabular}{lllllllllllllll}
$89)$ & 0,0 & 1 & - & - & - & - & 0 & - & - & 0 & 0 & \\
1,0 & & & & & & & & & & & & \\
$90)$ & 0 & 1,5 & 0,4 & 1 & 0 & 0 & 2,2 & 0 & 0,1 & 0 & 0 & \\
0,1 & & & & & & & & & & & & \\
$91)$ & - & - & 0 & - & 0 & 0 & - & - & 1 & 0 & 0,0 & 0 \\
$92)$ & 0 & - & 0 & - & - & - & - & 0 & 1 & 0 & - & - \\
\hline
\end{tabular}

Para Cahuana, cada cifra (o rango) indica el máximo número de aves presentes durante el mes ( $x$ indica que se observó la presencia de 1 é más aves pero no se hizo censo). En tablas 8, C y D las cifras indican el numero de aves contados en cada recorrido de censo; cuando se realizaron 2 ó 3 recorridos dentro del mismo mes, los resultados están enumerados consecutivamente.

(“-") indica que no se hizo observaciones en el mes indicado. 


\section{Casmerodius albus GARZA BLANCA GRANDE}

Es la más grande de las garzas blancas de la A mazonía (peso: $0.8-1.0 \mathrm{~kg}$ ), aproximándose al tamaño de la garza ceniza. Es también la más gregaria de las garzas: en el Pacaya se le ve mayormente en grupos y bandadas de hasta 50 aves; también se observan congregaciones de hasta cientos de aves, y realiza desplazamientos masivos estacionales dentro de la Reserva que incluyen hasta miles de aves. A nimales solitarios son menos frecuentes. No muestran comportamiento territorial.

\section{Preferencias de hábitat}

En contraste con la garza ceniza, la blanca ocupa principalmente las cochas y pantanos abiertos (pungales); frecuenta las tipishcas y orillas del Pacaya medio relativamente poco. Generalmente no entra en los caños y pozas interiores del bosque. Estas preferencias de habitat fueron muy evidentes también en los recorridos de censo (Cuadro2): en la cocha Tamara estaba presente en la mayoría de los conteos, mientras que en los tramos del río estaba mayormente ausente (en el tramo Cahuana - Mauca totalmente ausente). Al parecer, la garza blanca grande frecuenta las orillas del Pacaya medio casi únicamente cuando está migrando río arriba o abajo, o cuando está siguiendo a un cardúmen mayor de peces migrantes. Esto, sin embargo, no es el caso en el bajo Pacaya, donde el cauce del río es más amplio y las orillas son bajas, abiertas y pantanosas, por lo que constituyen parte del hábitat preferido de esta especie. En el bajo Pacaya está presente durante todo el año.

\section{Abundancia}

Los registros mensuales en Cahuana demuestran que la especie está presente en el área durante la mayor parte del año; está totalmente ausente en abril y mayo (Cuadro 2A). La abundancia en Cahuana muestra una fluctuación estacional muy amplia; entre enero y marzo se observan grandes bandadas circulando en el área, sumando más de 2,000 aves (Tabla 2A), que probablemente están desplazándose hacia las colonias de anidación (garzales). En junio aparece nuevamente en Cahuana -- generalmente alrededor de 500 aves (Tabla 2A) -- evidentemente de regreso de los garzales. En julio o agosto empiezan a emigrar hacia el bajo Pacaya, y para setiembre-diciembre quedan sólo unas pocas aves en el área (Tabla 2A). En resumen, la densidad poblacional en Cahuana muestra la siguiente fluctuación estacional:

$\begin{array}{lll}\text { Enero - M arzo } & \text { : Fluctuante }(0-\text { ca } 2,500 \text { aves }) & =0-\text { ca } 2,500 / \mathrm{km} 2 \\ \text { A bril - M ayo } & : \text { A usente } & =0 \\ \text { Junio-A gosto } & : \text { A bundante }(300-600 \text { aves }) & =\underline{\text { ca }} 300-600 / \mathrm{km} 2 \\ \text { Set. - Dic. } & : \text { Escaso }(0-7 \text { aves }) & =0-\text { ca } 7,4 / \mathrm{km} 2\end{array}$

En el tramo Cahuana-Tamara C. albus estaba presente en el $67 \%$ de los recorridos de censo. Cuando presente, los conteos oscilaban mayormente entre 1 y 4 aves (Cuadro 2B). En el tramo Cahuana-M auca no se observó ninguna ave de 
esta especie (Cuadro 2C). Estos resultados corroboran la poca presencia de C. albus en las márgenes del Pacaya medio. No obstante, en una oportunidad (marzo de 1991) se observó una congregación de 211 ejemplares en el tramo CahuanaTamara (Cuadro 2B), que probablemente estaba en tránsito hacia algún garzal. Excluyendo el periodo de abril-mayo, cuando generalmente la especie está totalmente ausente del Pacaya medio, y el citado caso insólito, tenemos para el tramo Cahuana-Tamara, una abundancia general de 0.03 aves $/ \mathrm{km}$ río. En la cocha Tamara la frecuencia de la presencia de estas garzas fue mucho mayor (Cuadro 2D). Excluyendo el período de la ausencia total de la especie del Pacaya medio (abril-mayo), hubo en termino medio, 5.34 aves presentes.

\section{C uadro 2}

Censo de Casmerodius al bus. A: Censos mensuales en el área de $C$ ahuana $\left(1.75 \mathrm{~km}^{2}\right) . \mathrm{B}$ : Conteos mensuales en el tramo Cahuana-Tamara $(48 \mathrm{kms})$. C: Conteos en el tramo Cahuana-M auca (12 kms). D: Conteos en la cocha Tamara. Para la explicación del significado de las cifras y símbolos vea Cuadro 2.

\begin{tabular}{lllllllllllll} 
A ño E & $F$ & $M$ & $A$ & $M$ & $J$ & $J$ & $A$ & $S$ & 0 & N & D \\
\hline A. & Cahuana & & & & & & & & & & & \\
$88)$ & $1000-$ & 26 & 30 & 0 & 0 & $300+$ & 600 & $\mathrm{x}$ & $\mathrm{x}$ & $\mathrm{x}$ & 1 & 2 \\
& 1500 & & & & & & & & & & & \\
$89)$ & 0 & $100-$ & $2000-$ & 0 & 0 & $300-$ & 50 & $100-$ & $1+$ & 5 & 1 & 1 \\
$90)$ & 0 & 150 & 2400 & & & 500 & & 150 & & & & \\
$91)$ & - & $2100-$ & 1500 & 0 & 0 & $200-$ & 200 & 1 & 0 & 7 & 7 & 0 \\
$92)$ & 2200 & - & 1 & - & 0 & - & - & - & 2 & 1 & $1+$ & 0 \\
& 2300 & & $100-$ & - & - & - & - & $20-30$ & 2 & 2 & - & - \\
\hline
\end{tabular}

B. Cahuana-Tamara $(n=28)$

\begin{tabular}{lllllllllllll}
$90)$ & 0 & 0.0 & 0.2 & 0 & 0 & 0 & 4.3 & 0 & 1 & 1 & 1 & \\
0.0 & & & & & & & & & & & & \\
$91)$ & 0 & - & 211 & - & 0 & 0 & - & - & 0 & 2 & 0 & 0 \\
$92)$ & 0 & - & 4 & - & - & - & - & 1 & 2 & 11 & - & - \\
\hline
\end{tabular}

C. Cahuana - M auca $(n=19)$

89-92) No se avistó ningún ejemplar en este tramo

D. Cocha Tamara $(n=38)$

89) $4.0 \quad 1$

0.0

90) $0-2.3$

0.0

2.3

0.31

$0 \quad 0$

6.63

$\begin{array}{lll}3.2 & 3 & 1\end{array}$

91)

$13-00$

210

$50-\quad 0$

92) 0

$30+$

3

4

100.1 


\section{E gretta thula GARZA BLANCA CHICA}

Esta pequeña garza blanca (peso $0.3 \mathrm{~kg}$ ) es netamente gregaria: generalmente anda en grupos pequeños y bandadas de hasta 50 aves; también forman ocasional mente congregaciones de hasta 200-300. Sólo raras veces se ven aves solitarias. No muestra comportamiento territorial.

\section{Preferencias de hábitat}

Como la garza blanca grande, también ésta pequeña ocupa principalmente las cochas y pantanos abiertos (pungales), y estas dos especies se asocian frecuentemente, formando bandadas mixtas. Debido a su preferencia por este tipo de hábitat, es una especie propia del bajo Pacaya; en el Pacaya medio circulan uno 0 algunos grupos y bandadas sólo en junio-agosto, y entre enero y marzo se ven varios ejemplares dentro de las bandadas de garza blanca grande que pasan por el área de Cahuana en su camino hacia los garzales. En los otros meses del año está ausente del Pacaya medio. En el Pacaya medio se le ve sólo raras veces en las orillas del río o tipishca y nunca en los caños y pozas del interior del bosque.

\section{Abundancia}

En Cahuana hemos registrado la presencia de $E$. thula en enero-marzo y junio- agosto (y un solitario en Octubre de 1988) (Cuadro 3A). El numero de aves presentes en junio-agosto varía anualmente desde unos pocos hasta 50 , Con un promedio de 14.9 (Cuadro 3A). Entre enero y marzo pasan por Cahuana unas 50- 100 aves, asociadas con las bandadas mayores de la garza blanca grande. En resumen, tenemos la siguiente abundancia promedio estacional en Cahuana:

$\begin{array}{ll}\text { Enero }- \text { M arzo } & : 0-100 \text { aves }=0-\mathrm{ca} 100 / \mathrm{km} 2 \\ \text { Junio-A gosto } & : 0-50 \text { aves }=14.9 \mathrm{krn2} \\ \text { Otros meses } & : \text { A usente }=0\end{array}$

Como se puede apreciar en el Cuadro 3B, en los 28 recorridos por el tramo Cahuana-Tamara se encontró esta ave en sólo 2 ocasiones: un grupo de 12 en marzo de 1991 y un solitario en mayo. Las 12 aves estaban asociadas con una congregación ya mencionada de 211 garzas blancas grandes, y evidentemente estaban de tránsito hacia algún garzal. En el tramo Cahuana-M auca no se observó ejemplar alguno. En base a estos datos y observaciones adicionales realizadas fuera del censo, podemos concluir que, en el Pacaya medio la garza blanca chica está presente en las márgenes del río sólo muy esporádicamente y su abundancia en ésas es virtual mente cero.

En la cocha Tamara la garza blanca chica fue 
encontrada 3 veces (Cuadro 3D); la abundancia promedio correspondiente sería 0.76 aves. Aunque las cochas constituyen parte del hábitat preferida de esta especie, su poca abundancia en la cocha Tamara refleja la escasa presencia en general de estas aves en el Pacaya medio. En las márgenes del bajo Pacaya se observa la mayor abundancia de esta especie en junio-julio; en enero, febrero y noviembre está generalmente ausente de éstas.

\section{Cuadro 3}

Censo de E gretta thula. A: Censos mensuales en el área de C ahuana (1.75 $\mathrm{km}^{2}$ ) B: Conteos mensuales en el tramo Cahuana-Tamara (48 kms). C: Conteos en el tramo C ahuana-M auca (12 kms). D: Conteos en la cocha T amara. Para la explicación del significado de las cifras y símbolos vea Cuadro 2.

\begin{tabular}{|c|c|c|c|c|c|c|c|c|c|c|c|c|}
\hline A ño & & $\mathrm{F}$ & $M$ & $\mathrm{~A}$ & $M$ & $\mathrm{~J}$ & $\mathrm{~J}$ & $\mathrm{~A}$ & $\mathrm{~S}$ & 0 & $\mathrm{~N}$ & D \\
\hline \multicolumn{13}{|c|}{ A. Cahuana } \\
\hline 88) & 8 & 0 & 0 & 0 & 0 & 0 & 50 & 50 & 0 & 1 & 0 & 0 \\
\hline 89) & 0 & 2 & $50-100$ & 0 & 0 & 20 & 12 & 10 & 0 & 0 & 0 & 0 \\
\hline 90) & - & $x$ & $3-4$ & 0 & 0 & 4 & 1 & 0 & 0 & 0 & 0 & 0 \\
\hline 91) & - & - & 0 & - & 0 & - & - & - & - & 0 & 0 & 0 \\
\hline 92) & $50-1$ & - & 0 & - & - & - & - & 2 & - & 0 & - & - \\
\hline \multicolumn{13}{|c|}{ B. Cahuana-Tamara $(n=28)$} \\
\hline 90) & 0 & 0.0 & 0.0 & 0 & 0 & 0 & 0.0 & 0 & 0 & 0 & 0 & \\
\hline \multicolumn{13}{|l|}{0.0} \\
\hline 91) & - & - & 12 & - & 1 & 0 & - & - & 0 & 0 & 0 & 0 \\
\hline 92) & 0 & - & 0 & - & - & - & - & 0 & 0 & 0 & - & - \\
\hline \multicolumn{13}{|c|}{ C. Cahuana - M auca $(n=19)$} \\
\hline \multicolumn{13}{|c|}{ 89-92) } \\
\hline \multicolumn{13}{|c|}{ D. Cocha Tamara $(n=38)$} \\
\hline 89) & 0.0 & 0 & - & - & - & - & 0 & - & - & 13 & 0 & 0.0 \\
\hline 90$)$ & 0 & 0.0 & 0.1 & 0 & 0 & 0 & 0.0 & 0 & 0.0 & 0 & 0 & \\
\hline \multicolumn{13}{|l|}{0.0} \\
\hline 91) & - & - & 0 & - & 0 & 0 & - & - & 0 & 0 & 15.0 & 0 \\
\hline 92) & 0 & - & 0 & - & - & - & - & 0 & 0 & 0 & - & - \\
\hline
\end{tabular}




\section{Butorides striatus GARZA TAMANQUITA}

Esta es la más pequeña de las garzas presentes en el área de estudio (peso $0.2 \mathrm{~kg}$ ). Es básicamente solitaria y territorial; aunque no forma bandadas, se observan concentraciones temporales semi-cohesivas de hasta 100-200 aves.

\section{Preferencias de hábitat}

Habita principalmente las márgenes inundadas del río, tipishca y cocha, con profusa vegetación hidromórfica y poca corriente (aguas lénticos). Por su pequeño tamaño la tamanquita puede, contrario a las otras garzas, posarse y caminar sobre alfombras flotantes de Pistia stratiotes y cazar saltamontes y otros invertebrados que abundan en este microhahitat, compartiéndolo con el tuquituqui (J acana jacana). Cuando un sector de una tipishca o cocha se cubre con Pistia se observan a menudo pequeñas concentraciones de 3-5 tamanquitas. No frecuenta los caños y pozas del interior de la tahuampa.

\section{Abundancia}

L os registros mensual es en Cahuana demuestran que la especie está presente en el área durante todo el año (Cuadro $4 \mathrm{~A}$ ). El número de aves presentes en Cahuana fluctuaba entre 1 y 6 ó 7, pero esta fluctuación no parece obedecer un patrón estacional definido; no obstante, en octubre tiende a ser muy escaso en Cahuana. En termino) medio hubo 3.1 aves, lo que equivale tina abundancia 0 densidad poblacional de 4.2 aves $/ \mathrm{km}^{2}$ en el área de Cahuana.

En el tramo Cahuana-Tamara, los conteos fluctuaban entre 0 y 24 aves (Cuadro 4B) con un promedio de 6. 1 aves. Tampoco en este tramo se observo un patrón estacional definido de la fluctuación, excepto tal vez una reducción de la población en noviembre-diciembre (Cuadro 4B). L os conteos de los años 91 y 92, y las observaciones adicionales realizadas en el bajo y medio Pacaya, parecen indicar que $B$. striatus realiza migraciones masivas y lentas por el curso del río, pero no en bandadas cohesivas sino en concentraciones sernicohesivas que abarcan kilómetros del curso del río. Probablemente están siguiendo concentraciones 0 cardúmenes de alevinos o peces pequeños que están avanzando lentamente por el río.

En término medio, la abundancia de $B$. striatus en este tramo del río es 0.13 aves $/ \mathrm{km}$ río. Los conteos realizados en el tramo Cahuana-M auca (Cuadro 4C) arrojan, igualmente, una abundancia promedia de $0.13 \mathrm{aves} / \mathrm{km}$ río.

B.striatus fue relativamente escaso en la cocha Tamara (Cuadro 4D): en término medio se encontró 0.76 aves.

También en las márgenes del bajo Pacaya está presente durante todo el año. 


\section{Cuadro 4}

Censo de Butoides striatus. A; Censos mensuales en el área de $C$ ahuana (1.75 $\mathrm{km}^{2}$ ). B: Conteos mensuales en el tramo C ahuana-T amara (48km). C: Conteos en el tramo Cahuana-M auca (12 kms). D: Conteos en la cocha Tamara. Para la explicación del significado de las cifras y símbolos vea cuadro 2.

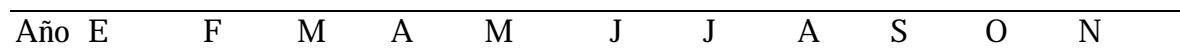

A. Cahuana

$\begin{array}{lcccccccccccc}89) & 2 & 4 & 5-6 & 3 & 3 & 2 & 4 & 4 & 3 & 1 & 2 & 2 \\ 90) & 4 & 4 & 1 & 3 & 3 & 3 & 2 & 1 & 1 & 1 & 2 & 4 \\ 91) & - & - & \mathrm{x} & - & \mathrm{x} & - & - & - & \mathrm{x} & \mathrm{x} & \mathrm{x} & \end{array}$

4-5

$5-6 \quad 5-6 \quad 4$

B. Cahuana-Tamara $(n=28)$

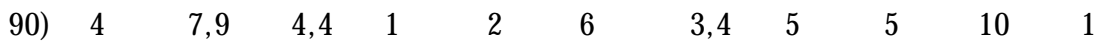

1,3

$\begin{array}{lllllllllllll}91) & - & - & 15 & - & 24 & 16 & - & - & 5 & 8 & 0 & 0 \\ 92) & 4 & - & 5 & - & - & - & - & 10 & 11 & 4 & - & -\end{array}$

C. Cahuana - M auca $(n=19)$

$\begin{array}{llllllllllll}89) & - & 1 & - & - & - & 4 & - & - & - & - & - \\ 90) & - & - & - & - & - & - & 2 & 5,1 & 2,0 & 1,1,3 \\ 91) & - & - & - & - & - & - & - & - & - & -\end{array}$

0

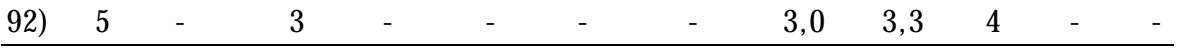

D. Cocha Tamara $(n=38)$

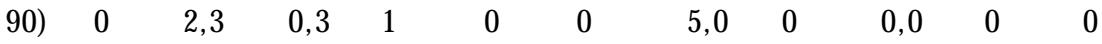
0,0

91)

0

92) $0 \quad-\quad 0$ 


\section{Pilherodius pileatus GARZA BLANCA}

P. pileatus es una garza de mediano tamaño (peso $0.5 \mathrm{~kg}$.), vive sola, en parejas y en grupos familiares (adultos con el prole del año). Entre julio y octubre se le ve también en pequeños grupos o congregaciones de hasta un máximo de 10 aves (Figura 3). No parece ser territorial. 


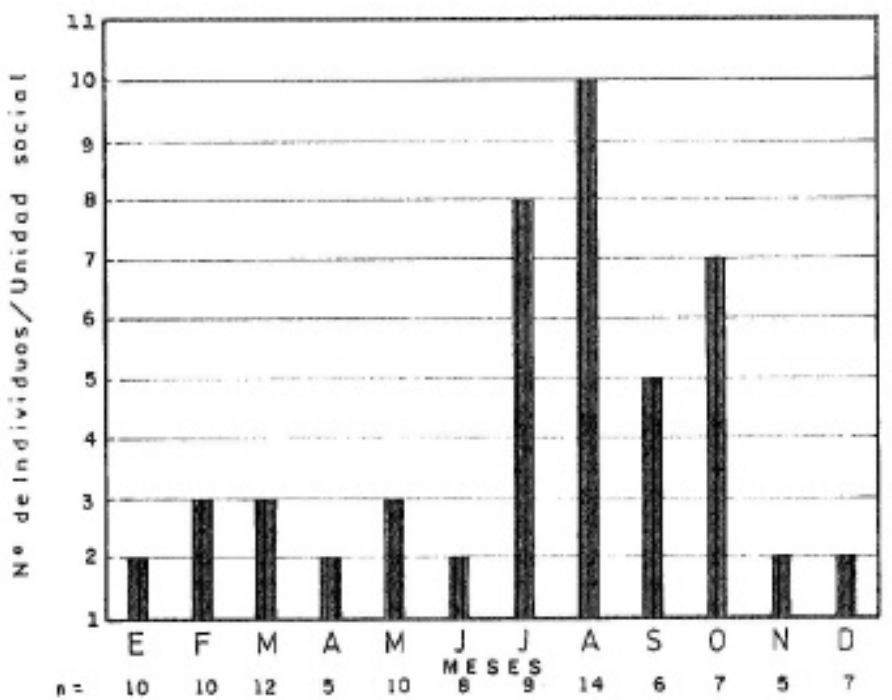

Figura 3. Los rangos mensuales de tamaño de las unidades sociales de Pilherodius pileatus observados en el río Pacaya medio en 1988-92 ( $\mathrm{n}=$ número de unidades observadas). 


\section{Preferencias de hábitat}

Esta especie frecuenta principalmente los pequeños caños, arroyos, pozas y charcos del interior del bosque y pantano, generalmente donde el agua tiene poca profundidad. En las orillas del río y tipishca se le encuentra sólo circunstancialmente, generalmente en la desembocadura de un cañito, arroyo 0 charco.

\section{Abundancia}

Las observaciones y registros mensuales en Cahuana demuestran que la especie está presente en el área durante todo el año (Cuadro 5A). Los censos mensuales indican una máxima abundancia en la temporada de estiaje, en juliooctubre (Cuadro 6A). Sin embargo, esta ave no realiza migraciones locales estacionales, y las diferencias estacionales en los resultados de los censos se deben principalmente al hecho de que estas aves se hacen más conspicuas durante el estiaje, cuando la tahuampa se seca y se concentran en lugares donde todavía quedan pozas, arroyos y charcos, muchas veces en lugares abiertos y cerca al río. Cuando el nivel del río crece e inunda la tahuampa, la población se dispersa al interior de la tahuampa y el censo de la población se hace muy difícil. Por ende, los conteos máximos, registrados anualmente en el período julio-octubre, son los que mejor reflejan la abundancia real de la especie en el área. Como se puede apreciar en la Tabla $6 \mathrm{~A}$, en término medio hay 8 aves en el área de Cahuana, 10 que equivale a una densidad poblacional de 8.4 aves $/ \mathrm{km}^{2}$

Según los datos disponibles, P. pileatus anida en marzo-mayo y los juveniles del año se dispersan principalmente en octubre-noviembre, por lo que las diferencias estacionales en los resultados de los censos mensuales reflejarían también, en parte, una reducción real y paulatina de la población debido a mortalidad, particularmente entre los juveniles dispersantes, durante la estación de la creciente del río y hasta el inicio del estiaje.

El Cuadro 6B y $\mathrm{C}$ da los resultados de los conteos de esta especie en los dos tramos de censo del río. Como se puede apreciar, la frecuencia de encuentros no muestra ningún patrón estacional y, como ya se indicó, $P$. pileatus frecuenta las márgenes del río solo circunstancialmente, por lo que los escasos encuentros con él en estos recorridos no reflejan bien su abundancia real en el área. En término medio, se encontraron 0.02 aves/ $\mathrm{km}$ río en el tramo Cahuana-Tamara y 0.04 aves $/ \mathrm{km}$ río en el tramo Cahuana-M auca. En los 38 conteos realizados en la cocha Tamara en 1989-92, no se observó ejemplar alguno de esta especie, lo que refleja su poca preferencia por este tipo de hábitat.

En las márgenes del bajo Pacaya se le ve a esta garza solo muy esporádicamente. 


\section{Cuadro 5}

Censo de Pliherodius pileatus. A; Censos mensuales en el área de $C$ ahuana $\left(1.75 \mathrm{~km}^{2}\right)$. B: C onteos mensuales en el tramo C ahuana-Tamara (48 kms). C: Conteos en el tramo Cahuana-M auca (12 kms). D: Conteos en la cocha Tamara. Para la explicación del significado de las cifras y símbolos vea cuadro 2.

\begin{tabular}{|c|c|c|c|c|c|c|c|c|c|c|c|c|}
\hline \multicolumn{2}{|c|}{ A ño $E$} & $\mathrm{~F}$ & $M$ & $\mathrm{~A}$ & $M$ & $\mathrm{~J}$ & $\mathrm{~J}$ & $\mathrm{~A}$ & $\mathrm{~S}$ & 0 & $\mathrm{~N}$ & $\bar{D}$ \\
\hline \multicolumn{13}{|c|}{ A. Cahuana } \\
\hline 88) & 1 & 3 & 2 & 1 & $1+$ & 2 & $3-4$ & 10 & 8 & 3 & $1-2$ & 2 \\
\hline 89) & 2 & 1 & $2-3$ & $2-3$ & $2-3$ & 2 & 4 & $4-7$ & 2 & $7-9$ & $1-2$ & 1 \\
\hline 90) & 3 & 1 & 1 & 3 & 1 & 1 & 8 & 2 & $1-2$ & $1-2$ & $2-4$ & 1 \\
\hline 91) & - & - & 1 & - & 1 & - & - & - & 3 & $4+$ & 1 & 1 \\
\hline 92) & 1 & - & - & - & - & - & - & 7 & $7-8$ & $7-8$ & - & - \\
\hline
\end{tabular}

B. Cahuana-Tamara $(n=28)$

$\begin{array}{lllllllllllll}90) & 0 & 0,5 & 1,0 & 0 & 0 & 2 & 0,8 & 1 & 0 & 0 & 0 & \\ 0,0 & & & & & & & & & & & & \\ 91) & - & - & 4 & - & 6 & 2 & - & - & 0 & 3 & 0 & 0 \\ 92) & 0 & - & 0 & - & - & - & - & 0 & 0 & 1 & - & -\end{array}$

C. Cahuana - M auca $(n=19)$

\begin{tabular}{|c|c|c|c|c|c|c|c|c|c|c|c|c|}
\hline 89) & - & 0 & - & - & - & 0 & - & - & - & - & - & - \\
\hline 90) & - & - & - & - & - & - & 2 & 0,0 & 0,1 & $0,0,0$ & - & - \\
\hline 91) & - & - & - & - & - & - & - & - & - & 0 & - & 0 \\
\hline 92) & 0 & - & 0 & - & - & - & - & 5,0 & 2,0 & 0 & - & - \\
\hline
\end{tabular}

D. Cocha Tamara $(n=38)$

Tigrisoma lineatum PUMA GARZA

Es una garza de tamaño mediano (peso $0.8-0.9 \mathrm{~kg}$ ), solitaria, territorial y seminocturno.

\section{Preferencias de hábitat}

Habita principalmente dentro de la vegetación boscosa de los terrenos inundados de las márgenes de hondonadas, pantanos, cochas, tipishcas y río; generalmente no deja verse desde el río o cocha, pero de noche delata a menudo su presencia por su vocalización nocturna inconfundible. En la temporada del 
estiaje, principalmente entre agosto y octubre, cuando su hábitat principal se seca por completo, sale a habitar en las orillas del río, tipishca y cocha; entonces es más fácil de detectar y la población puede ser censada. A unque normalmente es solitario, se observan ocasionalmente, en esta temporada, congregaciones pequeñas, de 2-4 animales, alrededor de alguna poza o charco mayor remanente de agua.

\section{Abundancia}

L os registros mensuales en Cahuana demuestran que la especie está presente en el área durante todo el año (Cuadro 6A). Conteos completos de la población de Cahuana en agosto-setiembre de 1990, 1991 y 1992 (Cuadro 6A) indican que la población se incrementó de 4 a 9 en ese lapso. Las densidades poblacionales anual es correspondientes serían $4.2,7.4$ y 9.5 aves $/ \mathrm{km} 2$, con un promedio de 7.0 aves $/ \mathrm{km}^{2}$. En esta especie los juveniles son reconocibles por su plumaje distintivo, lo que permite conocer más detalladamente la composición de la población, a saber:

A gosto de $1990 \quad: 4$ adultos, 0 juveniles.

Setiembre-Octubre 1991 : 4 adultos, 3 juveniles

A gosto-Setiembre 1992 : 5 adultos, 4 juveniles

Como se puede apreciar en el Cuadro 6, la puma garza se encuentra esporádicamente en las orillas del río fuera de la temporada agosto-octubre. En el tramo Cahuana-Tamara el número máximo anual de aves contadas varía entre 3 y 14 (Cuadro 6B): la abundancia promedio correspondiente sería 0.15 aves $/ \mathrm{km}$ río.

En el tramo Cahuana-M auca los conteos máximos anuales variaban entre 3 y 5 (Cuadro 6C), siendo la abundancia promedia correspondiente $0.33 \mathrm{aves} / \mathrm{km}$ río. Estos resultados sugieren que esta especie es más abundante en este tramo superior del río que más abajo. Por lo tanto, la abundancia promedio para todo el Pacaya medio se estima en 0.24 aves $/ \mathrm{km}$ río. En la cocha Tamara los encuentros con la puma garza fueron infrecuentes (Cuadro 6D): en termino medio hubo 0.40 aves presentes, si consideramos sólo los conteos obtenidos en la temporada anual de máxima detectabilidad (agosto-octubre). No se observó esta especie a las márgenes del bajo Pacaya, pero probablemente está presente en bajas densidades poblacionales, en el interior del bosque. 


\section{Cuadro 6}

Censo de Tigrisoma lineatum. A; Censos mensuales en el área de $C$ ahuana $\left(1.75 \mathrm{~km}^{2}\right)$. B: C onteos mensuales en el tramo Cahuana-Tamara (48 kms). C: Conteos en el tramo Cahuana-M auca (12 kms). D: Conteos en la cocha Tamara. Para la explicación del significado de las cifras y símbolos vea cuadro 2.

\begin{tabular}{|c|c|c|c|c|c|c|c|c|c|c|c|c|}
\hline A ño & $E$ & $\mathrm{~F}$ & M & A & $M$ & J & J & A & S & 0 & $\mathrm{~N}$ & $\mathrm{D}$ \\
\hline \multicolumn{13}{|c|}{ A. Cahuana } \\
\hline 88) & $x$ & $x$ & - & - & $x$ & $x$ & $x$ & $x$ & $x$ & $x$ & $x$ & $x$ \\
\hline 89) & $x$ & - & - & $x$ & - & $x$ & $x$ & $x$ & $x$ & $x$ & $x$ & $x$ \\
\hline 90$)$ & $x$ & - & - & $x$ & $x$ & $x$ & $x$ & 4 & $x$ & $x$ & $x$ & - \\
\hline 91) & - & - & $x$ & - & $x$ & - & - & - & 7 & $x$ & $x$ & $x$ \\
\hline 92) & $x$ & - & - & - & - & - & - & 9 & - & 4 & - & - \\
\hline
\end{tabular}

B. Cahuana-Tamara $(n=28)$

$\begin{array}{lllllllllll}90) & 0 & 0,0 & 0,0 & 0 & 0 & 0 & 1,0 & 3 & 2 & 0\end{array}$

0,0

91) - $\quad-\quad 1 \quad-000$

92) 0

(n=19)

89) - 1

90)

91)

92) 1

0

- $\quad-$

$\begin{array}{lllll}- & 1 & 14 & 1 & 2 \\ 5 & 3 & 0 & - & -\end{array}$

D. Cocha Tamara $(n=38)$

89) $0,0 \quad 0$

0,0

90) $0=0,1$

0,0

$1,0 \quad 1$

$0 \quad 0$

$0,0 \quad 0$

$1,0 \quad 0 \quad 0$

91)

$0 \quad-\quad 0 \quad 0$

$-$

0

$2 \quad 0,0 \quad 1$

92) 0

0

0

1

0




\section{Bubulcus ibis GARZA BLANCA "VAQUERA"}

Es una garza blanca pequeña (peso $0.3 \mathrm{~kg}$ ), inmigrante reciente en la A mazonía (originaria del Viejo $M$ undo y presente en el Perú desde la década del 50; Koepcke y Koepcke, 1964). Se asocia a menudo con el ganado, alimentándose de insectos sobre el lomo y en el pasto alrededor del ganado. En el Pacaya es escasa, pero en las orillas del U cayali es algo más abundante, particularmente donde hay ganadería. Es gregaria: en el Pacaya se la ve en grupos de 2-7 aves y también solitarias. A parentemente no es territorial.

\section{Preferencia de hábitat}

En el Pacaya frecuenta principalmente las cochas y orillas pantanosas del río.

\section{Abundancia}

Su distribución en el Pacaya se limita al sector bajo de la cuenca, donde la hemos observado presente en todos los meses del año excepto en enero, junioagosto y noviembre. En el Pacaya medio es sólo un visitante esporádico. En Cahuana ha sido observado sólo 5 veces en los últimos 5 años: 3 solitarios, una pareja y un grupo de 7 (Cuadro 7A).

En el tramo Cahuana-Tamara fue encontrada sólo una vez en los 28 recorridos de censo: un grupo de 4 aves en diciembre de 1990. En el tramo Cahuana-M auca no fue visto ninguna vez en los 19 recorridos de censo.

En la cocha Tamara, que está ubicada en el límite entre el bajo y medio Pacaya, esta ave fue encontrada 6 veces, sola y en grupos de 2 y 3 (Cuadro 7B).

La distribución temporal de las incursiones de B. ibis en el Pacaya medio y cocha Tamara muestran un patrón bien definido: acontecen en febrero-marzo y setiembre-diciembre; en el período abril-agosto no se observan incursiones, salvo un caso de una ave solitaria en mayo de 1988 (Cuadro 7). Esto nos permite definir su abundancia media estacional en la cocha Tamara de la siguiente manera:

- Febrero-M arzo y $\quad$ : abundancia $\sim=0.37$ aves

Setiembre-Diciembre

- Enero y A bril-A gosto : ausente. 


\section{Cuadro 7}

Censo de Bubulcus ibis. Distribución de los registros de visitas de B . ibis Cahuana en el período 1987-92. B: Conteos mensuales de B. ibis en cocha Tamara.

\begin{tabular}{|c|c|c|c|c|c|c|c|c|c|c|c|c|}
\hline \multirow{2}{*}{\multicolumn{13}{|c|}{$\begin{array}{l}\text { A ño } E \\
A . \quad \text { Cahuana }\end{array}$}} \\
\hline & & & & & & & & & & & & \\
\hline 87) & & & & & & & & & & & 2 & \\
\hline 88) & & & 1 & & & & & & & 2 & & \\
\hline 91) & & & & & & & & & & & 1 & \\
\hline 92) & & & 7 & & & & & & & & & \\
\hline \multicolumn{13}{|c|}{ B. Cahuana-Tamara $(n=28)$} \\
\hline 89) & 0,0 & 0 & - & - & - & & 0 & - & - & 0 & 0 & \\
\hline \multicolumn{13}{|l|}{0,0} \\
\hline 90) & 0 & 0,2 & 0,0 & 0 & 0 & 0 & 0,0 & 0 & 1,0 & 0 & 0 & \\
\hline \multicolumn{13}{|l|}{0,1} \\
\hline 91) & - & - & 0 & - & 0 & 0 & - & - & 0 & 0 & 0,0 & 1 \\
\hline 92) & 0 & - & 1 & - & - & - & - & 0 & 3 & 0 & - & - \\
\hline
\end{tabular}

\section{DISCUSION Y CONCLUSIONES}

\section{UNA EVALUACIÓN GENERAL DE LA METOdOLOGÍA DE CENSO de AVES ACUÁTICAS}

L a metodología de censo aplicada en Cahuana (modalidades 1 y 3) se basa en el conteo periódico de todas las aves acuáticas presentes en un área circunscrita y, cuando apropiadamente ejecutado, proporcionará información válida sobre densidades poblacionales. Sin embargo, tienen la desventaja de demandar mucho tiempo y esfuerzo, y aun así el área que se puede muestrear efectivamente es reducida. La metodología aplicada en el río y cocha (modalidades 1 y 2), en que se recorre periódicamente a motor una ruta, registrando las aves presentes, requiere mucho menos tiempo y esfuerzo y permite monitorear una zona mucho más amplia. Sin embargo, en vista de que nada se sabía sobre la aplicabilidad y efectividad de este método, realizamos ensayos y observaciones orientadas a evaluarlo. Para que los conteos de aves acuáticas en un recorrido a motor por el río sean lo más precisos posibles, es necesario que el censador pueda detectar y reconocer con certeza cada ave presente. En 1989 realizamos 10 recorridos de ensayo en el tramo principal de censo, de $48 \mathrm{~km}$ de longitud, con el fin de indagar si todas las especies de aves acuáticas eran contables con este método, Observaciones realizadas en estos ensayos indicaron que, con excepción de los tibes (Phaetusa simplex y Sterna superciliaris), el método no era adecuado para censar aves acuáticas menores, ya 
que las condiciones de censo (amplitud del río, velocidad del recorrido y el comportamiento de las aves), no siempre permitía detectar, reconocer y/o contar todos los individuos de estas especies. L as especies menores presentes en el área pero no incluidas en los conteos fueron: Heliornis fulica (pomponsito), Jacana jacana (tuqui-tuqui) y los catalanes, Ceryle torquata y Chloroceryle spp. No obstante, el censo de estas especies puede analizarse perfectamente recorriendo en canoa a remo tramos 0 áreas de muestreo más pequeñas. En vista de que los recorridos de censo se realizan de día, las garzas nocturnas de la región, Cochlearius cochlearius y Nycticorax nycticorax, no pueden ser censadas conjuntamente con las otras aves acuáticas. El Cuadro 8 presenta un listado de las aves acuáticas del Pacaya medio y una evaluación por especie de la aplicabilidad y efectividad de este método de censo.

Bajo las condiciones óptimas y constantes de censo, la proporción de la población total presente que el censador detecta depende principalmente de la conspicuidad de las aves (tamaño, color, comportamiento, etc.) y de su ubicación respecto al censador. Las especies incluidas en este censo son bastante conspicuos, jo que generalmente permite detectar todos los individuos ubicados a Io largo de la ruta de censo; el hecho de que por regla general suelen levantarse a vuelo ante la embarcación que se acerca, las hacen aun más fáciles de detectar. $\mathrm{H}$ ay, sin embargo, 2 especies que requieren una mayor atención en este sentido: Butorides striatus (garza tamanquita) y Anhinga anhinga (sharara). La primera es la mas pequeña de 55 garzas, y aunque suele levantarse a vuelo, algunos individuos ubicados dentro la vegetación acuática y más alejados de la línea de marcha de la embarcación pueden quedarse quietos y escapar de la detección. La sharara tiene a veces la costumbre de posarse sobre ramas o palos muy cerca a la superficie del agua y escabullirse buzeando $100 \mathrm{~m} 0$ aún más adelante de la embarcación, pasando así percibida (al parecer, esto lo hace cuando está en plena muda de las plumas alares e incapaz de subir a vuelo). Por ende, la densidad promedio real de estas dos especies es probablemente un poco mayor de lo indicado por los resultados del presente censo. En el bajo y medio Pacaya el curso del río está bordeado de frecuentes pungales, que forman parte del hábitat de varias especies de aves acuáticas, particularmente durante la temporada de creciente del río. Esto es especialmente el del camungo (Anhima cornuta), que habita principalmente los pungales, pero también las otras especies incluidas en el censo, con excepción del cushuri (Phalacrocorax olivaceus) y los tibes ( $P$. simplex y $\mathrm{S}$. superciliaris), los frecuentan mayor o menor grado. Todas las aves avistadas en estos pungales laterales fueron incluidas en el conteo, pero indudablemente quedaron algunas sin detectar en los sectores menos visibles desde el río. Por ende la densidad real de las especies presentes, con excepción del cushuri y los tibes, fue posiblemente un poco mayor, tal vez hasta un $5 \%$, de lo indicado por los conteos, particularmente en la época de creciente del río. En conclusión, a pesar de las limitaciones que acabamos de señalar, este todo de censo proporciona información válida y útil sobre la abundancia de las aves acuáticas. 


\section{Cuadro 8}

\section{Una evaluación de la aplicabilidad del método de censo de las aves acuáticas, que consiste en recorrer el curso del río en bote motor y contar las aves detectadas en el camino.}

\begin{tabular}{|c|c|c|}
\hline Especie & A plicable & Observaciones \\
\hline Phalacrocorax olivaceus & $\mathrm{Si}$ & \\
\hline Anhinga anhinga & $\mathrm{Si}$ & \\
\hline Ardea cocoi & $\mathrm{Si}$ & \\
\hline Casmerodius a/bus & $\mathrm{Si}$ & \\
\hline Egretta thula & $\mathrm{Si}$ & \\
\hline Butorides striatus & $\mathrm{Si}$ & \\
\hline Bubulcus ibis & $\mathrm{Si}$ & \\
\hline Pilherodius pileatus & No & $\begin{array}{l}\text { Presente solo esporádicamente en la } \\
\text { orilla del río. }\end{array}$ \\
\hline Tigrisoma lineatum & (Si) & Sólo durante el estiaje \\
\hline Nycticorax nycticorax & No & $\begin{array}{l}\text { Se le encuentra en orilla solo de } \\
\text { noche }\end{array}$ \\
\hline Cochlearius cochlearius & No & $\begin{array}{l}\text { Se le encuentra en la orilla solo de } \\
\text { noche }\end{array}$ \\
\hline Mycteria americana & $\mathrm{Si}$ & \\
\hline J abiru mycteria & $\mathrm{Si}$ & \\
\hline M esembrinibis cayennensis & No & $\begin{array}{l}\text { Presente solo esporádicamente en la } \\
\text { orilla del río }\end{array}$ \\
\hline Anhima cornuta & $\mathrm{Si}$ & Solo después de las 9:30 a.m. \\
\hline Cairina moschata & No & $\begin{array}{l}\text { Presente sólo esporádicamente en el } \\
\text { cauce del río }\end{array}$ \\
\hline Phaetusa simplex & $\mathrm{Si}$ & \\
\hline Sterna superciliari & $\mathrm{Si}$ & \\
\hline Heliornis fulica & No & Puede ser censado en canoa a remo \\
\hline J acana jacana & No & Puede ser censado en canoa a remo \\
\hline Ceryle torquata & No & Puede ser censado en canoa a remo \\
\hline Chloroceryle americana & No & Puede ser censado en canoa a remo \\
\hline Chloroceryle amazona & No & Puede ser censado en canoa a remo \\
\hline Chloroceryle india & No & Puede ser censado en canoa a remo \\
\hline Chloroceryle aenea & No & \\
\hline
\end{tabular}




\section{Abundancia}

En el Cuadro 9 se resume los resultados referentes a la abundancia de las garzas en el Pacaya medio. La abundancia de B. striatus es probablemente un poco mayor de lo indicado por los resultados del censo, por las razones indicadas en el capítulo sobre la evaluación del método de censo. A. cocoi es la garza más abundante en las márgenes del río y tipishca, con una densidad poblacional de 0.46 individuos $/ \mathrm{km}$ río. En cambio, en el ambiente de cocha $C$. albus es la especie de mayor abundancia; pero contrario a A. cocoi, su abundancia en el Pacaya medio acusa una fluctuación estacional muy amplia, desde la presencia de miles de aves hasta la ausencia total.

El censo poblacional más intensivo y completo realizado en el área de Cahuana reveló que, tomando en cuenta todos los tipos de hábitat acuática presentes, $P$. pileatus y $T$. lineatum son las especies de mayor densidad poblacional en el Pacaya medio.

Las observaciones realizadas en el bajo Pacaya indican que las dos últimas especies son poco abundantes allá y que $C$. albus y A. cocoi son las más abundantes. También la abundancia general de garzas parece ser mayor en el bajo Pacaya. Estas diferencias entre el curso bajo y curso medio del río se deben a las diferencias ecológicas entre éstos: en el bajo Pacaya predominan las cochas y pantanos extensos, mientras que en el Pacaya medio predomina el bosque de tahuampa y los pantanos y cochas son más reducidos.

\section{Cuadro 9}

Densidades poblacionales de las garzas diurnas en el Pacaya medio.

\begin{tabular}{llcl}
\hline $\begin{array}{l}\text { Especie } \\
\text { Tamara }\end{array}$ & $\begin{array}{l}\text { Área de } \\
\text { Cahuana } \\
\text { (aves/km²) }\end{array}$ & $\begin{array}{c}\text { Márgenes del río } \\
\text { (aves/l00 km de } \\
\text { río) }\end{array}$ & $\begin{array}{l}\text { Cocha } \\
\text { (total aves) }^{1}\end{array}$ \\
\hline Ardea cocoi & 5.3 & 46 & 0.55 \\
Casmrodius albus & $0-$ ca. 2500 & $(3)$ & $(5.34)$ \\
Egretta thula & $0-$ ca. 100 & 0 & 0.76 \\
Bubulcus ibis & 0 & 0 & 0.37 \\
Butorides striatus & 4.2 & 13 & 0.76 \\
Pilherodius pileatus & 8.4 & 3 & 0 \\
Tigrisoma lineatum & 7.0 & 24 & 0.40 \\
\hline
\end{tabular}

El número promedio de ejemplares presentes en cualquier momento dado. 


\section{Preferencias de hábitat}

Los resultados de este estudio, referentes a las preferencias de hábitat, resumidos en el cuadro 10, muestran como las especies de garzas diurnas presentes en el Pacaya medio reparten el macrohabitat acuática disponible entre sí, minimizando así la competición intraespecífica por los recursos. Las especies que tienen preferencias de hábitat muy similares entre sí, como $\mathrm{E}$. thula con $\mathrm{C}$. albus y $\mathrm{B}$. striatus con $A$. cocoi, se diferencian mucho en tamaño y por ende en cuanto al tamaño de los peces que capturan (Willard, 1985), lo que permite que coexistan sin competir por el alimento. B. ibis es de tamaño similar a E. titula, pero muy escasa en el Pacaya. La relación entre $T$. lineatum y $P$. pileatus es menos clara, pero el hecho de que la primera es parcialmente nocturna y más sedentaria que la segunda probablemente minimiza cualquiera competición que pudiera haber entre éstas. Las dos especies restantes $N$. nycticorax y $C$. cochlearius, también son de tamaño mediano, pero de hábitos totalmente nocturnos.

\section{Organización social}

EI Cuadro 11 resume la información obtenida referente a la organización social de las especies estudiadas. Como se puede apreciar, las especies que habitan principalmente en las cochas y pungales, que se caracterizan por ser ambientes comparativamente amplios y abiertos, son gregarios y no muestran comportamiento territorial. En contraste, las especies que habitan principalmente en las márgenes del río, en los caños y el inferior de la tahuampa, son mayormente solitarios y territoriales. $L$ a especie que mayor versatilidad muestra en el uso de hábitat -- A. cocoi -- es también la más flexible en cuanto a su organización social: en las orillas del río, tipishcas y caños muestra a menudo comportamiento territorial pero también se observan a menudo grupos y congregaciones. 


\section{Cuadro 10}

Preferencias de hábitat de las garzas diurnas en el Pacaya medio

\begin{tabular}{|c|c|c|c|c|c|}
\hline Especie (peso) & Río & Tipishca & Cocha & Pungal & $\begin{array}{l}\text { Caño/ } \\
\text { Tahuampa }\end{array}$ \\
\hline $\begin{array}{l}\text { Ardea cocoi } \\
(1-5-2 \mathrm{~kg})\end{array}$ & +++ & ++ & + & ++ & + \\
\hline $\begin{array}{l}\text { Casmerodius albus } \\
(0.8-1 \mathrm{~kg})\end{array}$ & + & + & +++ & +++ & \\
\hline $\begin{array}{l}\text { Tigrisoma lineatum } \\
(0.8-09 \mathrm{~kg})\end{array}$ & + & + & & ++ & +++ \\
\hline $\begin{array}{l}\text { Pilherodius pileatus } \\
(0.5 \mathrm{~kg})\end{array}$ & + & + & & + & +++ \\
\hline $\begin{array}{l}\text { Egretta thula } \\
(0.3 \mathrm{~kg})\end{array}$ & & & +++ & +++ & \\
\hline $\begin{array}{l}\text { Bubulcus ibis } \\
(0.3 \mathrm{~kg})\end{array}$ & & & +++ & & \\
\hline $\begin{array}{l}\text { Butorides striatus } \\
(0.2 \mathrm{~kg})\end{array}$ & +++ & ++ & ++ & + & \\
\hline
\end{tabular}

${ }^{1}$ En el Pacaya medio esta especie es sólo un visitante esporádico.

$+++=$ Hábitat preferido; $++=$ de uso frecuente; $+=$ de uso poco frecuente. 


\section{Cuadro 11}

\section{Organización social de las garzas diurnas en el Pacaya medio.}

\begin{tabular}{|c|c|c|c|}
\hline Especie & $\begin{array}{l}\text { Hábitat } \\
\text { principal }\end{array}$ & $\begin{array}{l}\text { Organización } \\
\text { Social }\end{array}$ & $\begin{array}{l}\text { M uestra } \\
\text { comportamiento }\end{array}$ \\
\hline $\begin{array}{l}\text { Casmerodius albus } \\
\text { Egretta thula } \\
\text { Bubulcus ibis } \\
\text { Ardea cocoi } \\
\text { Butorides striatus } \\
\text { Pilherodius pileatus } \\
\text { Tigrisoma lineatum }\end{array}$ & $\begin{array}{l}\text { cocha/pungal } \\
" \\
" \\
\text { río } \\
" \\
\text { caño/tahuampa } \\
"\end{array}$ & $\begin{array}{l}\text { gregaria } \\
\text { gregaria } \\
\text { gregaria } \\
\text { solitario y } \\
\text { semi- gregaria } \\
\text { solitaria } \\
\text { solitaria y } \\
\text { grupo } \\
\text { familiar } \\
\text { solitaria }\end{array}$ & $\begin{array}{l}\text { no } \\
\text { no } \\
\text { no } \\
\text { si } \\
\text { si } \\
? \\
\text { si }\end{array}$ \\
\hline
\end{tabular}

\section{BIBLIOGRAFIA}

ENCARNACION, F. 1985. Introducción a la flora y vegetación de la A mazonía peruana; estado actual de los estudios, medio natural y ensayo de una clave de determinación de las formaciones vegetales en la llanura amazónica. Candollea, 40: 237-252.

HANCOCK, J. y J. KUSHLAN, 1984. The Herons Handbook. Harper \& Row, N ew Y ork, 288 pp.

KALLIOLA, R. y M. PUHAKKA, 1993. "Geografía de la Selva Baja Peruana". pp. 9-21, en: Amazonía Peruana. Vegetación húmeda tropical en el Ilano subandino (Editado por R. Kalliola, M. Puhakka y W. Danjoy). Proyecto A mazonía. Univ. de Turku (Finlandia) y Oficina Nacional de Evaluación de Recursos Naturales (Lima, Perú).

WILLARD, D.E. 1985. Comparative feeding ecology of twenty-two tropical psicivoes. Ornith. Monographs. NO 36, pp. 788-797, Amer.. Ornith. Unión, W ashington, D.C. 
SOINI, P. 1992. E cología de las aves acuáticas, Parte 1. Informe de Pacaya N 0 37. IIAP y COREPASA, Iquitos.

KOEPCKE, H. W. y M. KOEPCKE, 1964. Las aves silvestres de importancia económica del Perú. - V. Ministerio de Agricultura. Lima, pp. 33-40. 